\title{
Image of "Ideal Doctor" as Basis of Effective Communication between Child and Doctor
}

\author{
Ekaterina Ruslyakova ${ }^{1, *}$, and Alissa Zelenskaya ${ }^{2}$ \\ ${ }^{1}$ Institute of Humanitarian Education, Nosov Magnitogorsk State Technical University, Russia \\ ${ }^{2}$ Nosov Magnitogorsk State Technical University, Russia
}

\begin{abstract}
The article presents the results of the research of children, their ideas about an ideal doctor, medicine and health in general as the basis of effective communication of a child and a doctor in the medical process. Effective pediatric care is possible only with competent professional communication of the doctor with the child. This requires an understanding of how the child perceives the doctor, his idea of him, past experience, an "ideal" image. It is revealed that the nature of relationships is important for the child first of all and not the interior or exterior. An image of the "Ideal Doctor", as well as a positive correlation between the scales the "Idea of Health" and the "Idea of the Doctor", was found. Properly organized communication is sure to help to reduce the emotional discomfort of the child, the formation of adequate ideas about the child's health and the degree of responsibility for it.
\end{abstract}

The most important and the least certain thing in the profession of a pediatrician is the interaction and communication with the patient-child. Studies were conducted in a group of 55 randomly selected women with children between 0 and 16 years of age, using standardized interviews to gather descriptions of typical situations of the "bad" and "good" interaction with a doctor about a child. The most unexpected result was the absence of the child as an active person and the absence of the results of treatment [10].

Effective pediatric care is possible only with the competent professional communication of the doctor with the child. This requires an understanding of how the child perceives the doctor, his idea of him, past experience, "ideal" image. Knowledge of the child's ideas about the doctor helps to establish a better contact between the doctor and the child will satisfy the need for help and emotional communication in a small patient. If the doctor fixes his attention on the somatic distress of the child-patient, the personality of this child is perceived by him only through the prism of the disease, and then the personality and the inner world of the child, his worries and fears slip away. This situation puts the doctor away from the child-patient, and therefore, from a really suffering person further. The doctor and the child do not interact; do not trust each other [7, 8]. As a result, the effectiveness of diagnosis and treatment is lower than it could have been [3]. Therefore, a child with his pain and anxiety should always be in the first place for a doctor.

What do children think about the whole situation? How do they see the doctor? What doctor will really help the child, to not only relieve symptoms, but also help to find peace of the mind?

The aim of the study: to reveal the idea of modern healthy children about doctors.

The study involved healthy children of primary school age. All the children showed interest, answered the questions, and carried out tasks with pleasure. Participation in the study was voluntary.

It is supposed that the idea of children of primary school age about the doctors has a range of negative experiences, they are afraid of them; the image of the "ideal" doctor in children is similar to the image of Dr. Dolittle described in the fairy tale by K. Chukovsky - a doctor is the best, ideal for children.

Representation is a mental process, as a result of which previously experienced events and previously perceived objects and objects are reflected, generalized, transformed; knowledge and understanding, based on experience, a structural element of the worldview. Representation is a transitional stage from concrete images to abstract concepts, from sensations to thinking. At the age of 7 to 9 years, children develop an intensive development associated with the development of arbitrariness. At the younger school age, children are able to arbitrarily call forth the necessary representations, at this time the formation of individual differences in perceptions occurs in children. Emotional tension encourages the formation of the image of an "ideal" doctor who has the opportunity to provide more effective help. Clarifying the ideas of healthy children about doctors, both desirable and real, will help make the process of doctor-child interaction productive for treatment and accelerate rehabilitation. Each patient, on

* Corresponding author: ekaterina-ruslyakova@yandex.ru 
the basis of cultural influences (the views of the society about the doctor), past experience of communicating with representatives of the medical profession (and generally with respected persons) and the nature of the expected help, has a certain image of a doctor (standard) that can satisfy his need for help and emotional communication. A small degree of similarity between the appearance of the ideal and the attending physician throughout the entire stay in the clinic may reflect a low quality of communication with the doctor and dissatisfaction with the treatment. Knowing and recording by the doctor the patient's image of an "ideal" doctor help to establish a better contact between them. Important conditions that determine the establishment of a doctor's contact with a patient are the latter's ideas about the doctor based on past experience and the nature of the first conversation with which the treatment process begins. Of course, there are no ideal doctors, as there is nothing ideal in the world, but in many scientific studies "ideal models" are often used. These are models that meet our needs and meet our desires, ideas. Let us try and imagine an "ideal" doctor who will be able to provide the child with competent help. Remember now: "Heals all - heals a good doctor Aybolit ..." When K. Chukovsky wrote these lines for children, he, of course, intuitively identified here the two main features of the ideal doctor, which he wants to introduce to the little reader of Aibolit. First: he treats one - all, that is, all diseases. So, it has the widest knowledge. The second feature is kindness. Kindness, should not be manifested in fulfilling the caprices of the patient, but in courtesy, sensitivity, compassion, responsiveness, the ability to listen carefully and answer questions. The initial stage in the study consisted of the task: "Draw the best doctor", the words "good" and "doctor" were deliberately avoided and no additional explanations or comments were made to avoid drawing children's drawings and not to promote stereotyping and use of the plot template in the drawings. Children were offered to express in a free form with the help of pencils, markers or paints the way they represent the best doctor. The use of projective methods enables the author to project reality and interpret it in his own way. Researchers of children's drawings emphasize that drawing is a kind of story and, in essence, does not differ from a verbal story. In "drawings on a given topic" (ie, in the situation of a standard pictorial task), there is much more information about the representations of the person drawing them than in a simple handwritten text, therefore such drawings are a very powerful psychodiagnostic tool.

To study the quality of communication, the ideas about doctors and their attitude to them we used the techniques of "Ideal Doctor's Drawing" and "Unfinished Sentences" developed by Kagan V. E. and Shats I. K. $[4,5]$.

At primary school age, children are able to cause the necessary views arbitrarily. At this time, there is formation of individual differences in views of children. Emotional stress leads to the formation of the image of the "ideal" doctor, who has the ability to provide more effective assistance. The clarification of the views of healthy children, the doctors, the desired and the actual, will help to make the process of interaction "the doctor the child" productive for treating and accelerate rehabilitation.

The emotional attitude of children to doctors is very different. But in many drawings (38\% - portraits) emotional fixation on the figure of the doctor, involvement in the process of social relations are expressed. The head of an adult is the most important organ associated with the emotional comfort of the child, "the person is an important center of communication, the social part of life" [9, p. 37-38].

1. $13 \%$ of children have a pronounced emotional stress in relation with doctors. The ends of their sentences "When I see a doctor...", "When I first came to the doctor because of illness..." were the following: "begin to cry", "frightened", "made an injection" "really creepy". $61 \%$ of children are afraid of doctors, their sentences, as a rule, ended like this: "afraid", "shy", "a little scared", "scary a bit." They would like to avoid a possible contact with doctors, to keep at a distance from them.

According to the features of parts of the figure, we can conclude that the painter was in a state of internal tension. It was found that in most children, regardless of age, the area of the shaded surface occupies at least half of the figure, which may indicate high emotional intensity of the experience of interaction with the doctor and in general issues of the medical character.

Despite their young age, $26.7 \%$ of children, who have already had negative experience of interaction with doctors, completed the sentences beginning with the words "The Doctor is...", "Most doctors are ..." with the phrases: "zombies", "villains", "wicked". Children's age is characterized by activity and energy, and it is just necessary to take into account these features of a sick child. Excitable, irritable, capricious children need emotional discharge [1]. If the doctor begins to behave strictly and directly, it causes only an even greater dysphoric reaction, mood disorder and provokes aggressive behavior of a small patient in relations to the doctor, treatment and a medical institution as a whole [2].

2. $26 \%$ of children said they were not afraid of doctors. Their sentences ended with the phrase: "I'm not afraid", "I like", "laugh", "gave the toy." It is possible to assume the existence in their life of pleasant memories about the interaction with the doctor and about understanding of the importance of medical examination and medical procedures. $53,3 \%$ of children remember the doctor as a good man. The children finished the sentences beginning with the words: "the Doctor is...", "Most doctors..." in the following way: "a saver", "a psychologist", "a doctor", "a person", "a helper".

3. $20 \%$ of children are focused on the activities of the doctor and on information experience: "doctor", "the person who treats", "treats people", "inspects", "makes injections", "walks around the offices", "does what he wants", "does what he can". The doctor is not bad and not good, he is just doing his job. It can be said that in this case the general awareness and knowledge about the doctor's profession, treatment or protective mechanism rationalization works. 
Children's opinions of the doctors differed in the following points: "go somewhere"/ "sit at home", "make injections"/ "do not make injections", " treat badly "/ "treat well", "help"/ "do not help", that is, from the point of view and experience of children it may be rather different in real life.

Unfortunately, only a few people (13\%) showed high literacy in general. $87 \%$ of children have low literacy. Preservation of health and care of children is associated with the rejection of sweets and a visit to the doctor. This means that the preservation of health is an important, but a very difficult, unpleasant process.

$35 \%$ of children are very worried about their health. As a result of conversation with parents it became clear that these are often sick children or one of their family members is seriously ill. Most children do not worry about their health, but they know that it is very important. $7 \%$ of children emphasize the importance of health and consider themselves absolutely healthy people. The following research did not come across the children who do not care about their health.

In general, the children were able to introduce the image of an "ideal" doctor.

An "ideal "doctor is "kind" - (70\%)," good", "the best in the world", "polite", "caring", "cheerful".

Instructions for the activity - 45\%: "attending", "working", "always goes to work", "treats animals", "treats most of all", "does not do injections", "does not speak rudely", "treats kids", "helps", "does not hurt", "does not put in the hospital", "loves children", "gives candy", "allows you to do whatever you want", "does me well".

There were references on specific people, with fixation on their images: "mother", "my doctor", "my grandmother", "my aunt", "a vet", "a psychologist", "a dentist", "a chief doctor", "a nurse " - 25\%.

The children also assume where such an "ideal" doctor can be met:" in the best policlinic of the world", "there are such doctors" - 98\%, "there are no such doctors" - 2\%.

The results obtained with the help of the study allowed identifying the following characteristics of the attitude to the doctor: 1) all patients highly value primarily emotional and moral-ethical traits of the personality of the doctor; 2) almost none of the patients value professional qualities; 3) no one evaluates intellectual and physical qualities.

Using average values, we have done the analysis of the relationship of the scales of the methodology "Unfinished Sentences" by means of the statistical programme Statistika 6 with the help of the Method of Linear Correlation. A strong positive correlation $(\mathrm{r}=$ $0,78$ at $p<0,05)$ between the variables of the "Unfinished Sentences" methodology: the "Idea of Health" scale and the "Idea of the Doctor" scale has been obtained. Thus, it can be said that in connection with healthy children, their health is associated with the activities of a real doctor, and is presented in the form of a passive, dependent position.
At the end of our research work, we can say that the hypothesis that we put forward at the beginning of the research has been confirmed.

Thus, it is necessary to take into account the specific ideas of the child about the doctor, health and treatment, to continue their study, to correct the image of the doctor if it is not productive [6]. This will significantly reduce the emotional discomfort of the child, avoid secondary stress, stress associated with diagnostic and therapeutic methods, dispose a little patient to follow necessary recommendations, procedures, assistance, as well as to form an adequate idea of the child's health and the degree of responsibility for it. It is also desirable for children to improve their literacy and gain knowledge about their body, harmful or useful factors affecting it, knowledge about doctors, health, medicine, preventive measures, and most importantly, the formation of a correct lifestyle from an early age.

The author expresses a deep gratitude to his teacher and expert mentors, Mamaichuk Irina Ivanovna, Professor of St. Petersburg State University; Makhnevoy Lyudmila Andreevna, doctor of the highest category, Children's polyclinic No6, Magnitogorsk; Musiychuk Marina Vladimirovne, Professor of Nosov Magnitogorsk State Technical University, Russia.

\section{References}

1. V. K. Kolondaev, Y. F. Panina, Medical Psychology in Russia: electron. Science journ 1 (2009), URL: http:// medpsy.ru (date of access: 05.03.2018)

2. V. Reutskaya, R. V. Savkina, E. E. Ruslyakova, L. V. Mezentseva, O. V. Gribova, International Journal of Applied Business and Economic Research 15(11), 255-263 (2017)

3. E. E. Ruslyakova, E.M. Razumova, The European Proceedings of Social \& Behavioural Sciences EpSBS, 844-850 (2017)

4. R. C. McEachan, M. Conner, N. Taylor, R. J. Lawton, Health Psychology Review 5, 97-144 (2011)

5. E. D. Isaeva, V. E. Kagan, Psycho-diagnostic methods in Pediatrics and pediatric Psychoneurology (PMI, S.-Pb., 1991)

6. E. E. Romycina, Questions of Psychology 1, 39-47 (2006)

7. E. V. Svistunova, Nurse 6, 47-52 (2012)

I. Ajzen, Psychology and Health 26, 1113-1127 (2011)

8. A.G. Billings, R.H. Moos, Journal of Behavioral Medicine 4(2), 139-157 (1981)

9. E. E. Ruslyakova, Psychological characteristics of adhesives suffering from bronchial asthma and psychological correction methods, (St. Petersburg, $\mathrm{PhD}$ dissertation (Psychology), S.-Peterb. gos. universitet, 2004)

\section{Summary}

